\title{
Copia versus original-múltiple. Una relación dialógica en el arte gráfico reproducible
}

\section{Copy versus original-multiple. A dialogic relationship in the reproducible graphic art}

\author{
Hortensia Mínguez García \\ Universidad Autónoma de Ciudad Juárez, Chihuahua, México. \\ Instituto de Arquitectura, Diseño y Arte. Departamento de Diseño. \\ horteminguez@gmail.com
}

Recibido: 11 de octubre de 2011

Aprobado: 14 de marzo de 2012

\section{Resumen}

El concepto de obra gráfica dentro de la praxis del arte gráfico seriable y/o reproducible, ha ido permutando en paralelo a nuestra forma de concebir y acotar legislativamente ideas como copia, reproducción, creación, múltiple, original, edición, etc. ¿En qué contexto comenzamos a considerar al concepto de copia peyorativamente? ¿Se debe esto al diseño del modelo sistémico y regulador que ideamos para proteger los derechos de los artistas ante la reproducción de sus obras gráficas? El presente texto aborda la relativización que los procesos creativos interdisciplinares del artista contemporáneo han producido respecto al concepto de obra gráfica y su tradicional dicotomía "copia versus original-múltiple".

Palabras clave: Arte gráfico, reproductibilidad, original, copia, múltiple.

Mínguez García, H. (2013): Copia versus original-múltiple. Una relación dialógica en el arte gráfico reproducible. Arte, Individuo y Sociedad, 25(1) 77-93

\begin{abstract}
The concept of graphic work in the practice of graphic art (seriable and/or reproducible), has changed in parallel to our way of thinking and delimit legislatively ideas as limit copying, reproduction, creation, multiple, original, edition, etc. In what context we begin to consider the concept of copy pejoratively? Is this because the design of regulatory systems that we devised to protect the rights of artists to reproduce his graphic works? This text addresses the relativization that the interdisciplinary creative processes of contemporary artists have produced on the concept of graphic art, and on the traditional dichotomy "copy versus multiple-original".
\end{abstract}

Key Words: Art graphic, reproducibility, original, copy, multiple.

Mínguez García, H. (2013): Copy versus original-multiple. A dialogic relationship in the reproducible graphic art. Arte, Individuo y Sociedad, 25(1) 77-93 
Sumario: 1. Prefacio, 2. Evolución del concepto de copia como original múltiple, 3. Hacia la construcción de un nuevo concepto de original en la gráfica. Referencias.

Este artículo recoge resultados de la investigación “Gráfica contemporánea seriable: del Grabado Matérico al electrográfico" financiada por el Programa PROMEP, México

\section{Prefacio}

La imagen, como elemento de comunicación visual, tiene un papel de relevancia inconmensurable pues, gracias a su carácter visualizable, expresivo, reproductivo y propagativo, el hombre ha podido cultivarse cultural e intelectualmente.

Antes de la llegada de la fotografía, el offset o la era digital, los métodos de reproducción de la imagen como la xilografía, el grabado, la litografía o la serigrafía, todos ellos ligados a la praxis artística, propiciaron la culturización y la alfabetización visual a través de la generación y la multiplicación de la imagen durante siglos.

Sin embargo, las técnicas gráficas que nacieron bajo la premisa de reproducir una imagen tallada, incidida, o grabada directa o indirectamente en una matriz $\mathrm{n}$ veces por medio de su estampación-impresión, se vieron sumidas al cerco de las "artes menores", pues donde la reproductibilidad podría convenir como una de las más fantásticas particularidades de este medio de expresión, se convirtió en su mayor lápida durante siglos.

Hoy en día, entendemos con gran claridad la diferencia entre grabado de reproducción o de interpretación versus el original o de creación. El primero, constituía históricamente el primer acto de aplicar un procedimiento industrial al campo del arte, y más concretamente al de la representación, ligándose en dicho sentido, a subsidiar la difusión de las obras de las Artes Mayores, como a divulgar y preservar la historia y los avances científicos por medio de la reproducción de imágenes de carácter predominantemente descriptivo. Fines utilitarios, que como bien relató William M. Ivin, subordinaban al grabado en general a ser por encima de todo, "un lenguaje al servicio de la difusión y propagación de la cultura". (Ivins, W.M. Jr., citado en Ramos, J.C., 1992, p. 20)

Por su parte, el grabado de creación, es decir, aquel generado por pura autoconveniencia y deseo de un artista de expresar su visión del mundo o de externarse a sí mismo, se recluyó a una práctica muy reducida. De hecho, las instituciones educativas y Academias retuvieron el progreso de este arte al tratarlo más como un oficio hasta finales del s. XIX principios del s. XX, que como un medio más de expresión lleno de infinitas posibilidades expresivas.

Sin embargo, desde el s. XX, el arte gráfico ligado al uso de técnicas que permiten la reproductibilidad de la imagen ha cambiado de manera sustanciosa convirtiéndose en uno de los medios expresivos predilecto de muchos artistas. En este sentido, con el paso del tiempo, según la forma de pensar, hacer y producir la imagen, hemos cambiado nuestra forma de entender para qué servían los métodos de reproducción de imágenes tradicionales, influyendo ello, en nuestra concepción de conceptos como autor, único, original, copia, reproductibilidad, edición seriada controlada, etc. dentro de esta área de conocimiento. ¿Se consideraba un acto de plagio si un grabador del 
s. XIII reproducía la obra de otro grabador? ¿Cuándo aparece el concepto de copia o el de derecho de autor y por qué? ¿En qué contexto comenzamos a considerar al concepto de copia peyorativamente? ¿Se debe al diseño del modelo sistémico y regulador que ideamos para proteger los derechos de los artistas ante la reproducción sus obras gráficas? Estas serán algunas de las preguntas que soslayaremos a lo largo del texto con la finalidad de concluir en la relativización que los procesos creativos interdisciplinares del artista contemporáneo han producido respecto al concepto de obra gráfica y su tradicional dicotomía "copia versus original-múltiple" que creíamos haber delimitado a finales del s. XX.

\section{Evolución del concepto de copia como original múltiple}

Cada uno de los diferentes engranajes que fueron dando forma a las primeras acotaciones legales de derechos de autor, producción y reproducción controlada del arte gráfico seriable, están directamente vinculados a una serie de acontecimientos que se remonta al Renacimiento.

Hasta las postrimerías del s. XIX, la preocupación general por regular una obra no era tan relevante ni para los artistas ni para los comerciantes. De hecho, en el renacimiento todavía no se cuestionaban ni la autenticidad, ni la originalidad de una obra gráfica reproducible. De ahí que, Rosa Vives apuntara a que, "en todo el grabado antiguo hasta finales del siglo XIX, las tiradas eran ilimitadas y las estampas no se numeraban ni se firmaban”. (Vives, R., 2003, p. 172)

Durante la Edad Media, por ejemplo, los mismos artistas no se preocupan por firmar las obras para hacer alarde y presencia de que éstas eran de su propia autoría puesto que la conceptualización del término "original" hacia la copia reproducida no existía como tal y la praxis de copiarse unos artistas a otros sin ningún tipo de permiso, contrato o acuerdo hablado, era un hábito muy común.

La incorporación de anagramas a las matrices o a las estampas, como elementos heráldicos o inscripciones que distinguen el nombre del artista, el grabador, el impresor o la casa editorial, fue una práctica que se introdujo bastante parsimoniosamente a partir del Renacimiento. Las razones básicas que impulsaron este cambio fueron, sin duda, muy lógicas y naturales. Con la entrada a la época floreciente del renacimiento, las estampas empezaron a cobrar mayor valor mercantil gracias al auge del coleccionismo. Una actividad que promovió a su vez, que los grabadores incursionaran en la inclusión de anagramas para constatar el origen de sus obras ya que, a diferencia de la pintura o la escultura, la obra impresa era un producto de fácil adquisición y transporte a diferencia del resto, y por ende, un medio de promoción incuestionable.

Por otra parte, el nuevo estatus social del artista renacentista y la inversión que los mecenas y coleccionistas hacían con su obra impulsaron, para el beneficio de ambas partes, la necesidad de proteger la autenticidad de sus ejemplares ante cualquier intento de plagio, así como los derechos de propiedad y la tasación ecuánime de sus adquisiciones e inversiones. 
No es nuevo, tomar como ejemplo, el caso de protesta formal por plagio que Durero presentó en Venecia en 1504 contra Marcantonio Raimondi tras enterarse de que este afamado grabador italiano osadamente había recaudado una gran suma de dinero copiando algunas de sus obras de su serie Life of the Virgin como "Meeting of St. Anne and St. Joachim at the Golden Gate", (fig.1 y fig.2).

Los compradores de la época, pensaban que adquirían grabados trabajados directamente por el artista alemán. La técnica era prácticamente idéntica, el tamaño de las placas también, e incluso, las estampas presentaban el inconfundible monograma que siempre había utilizado Durero, "AD". Totalmente enfurecido, Durero decidió viajar de Flandes hasta Venecia para presentar una queja ante el gobierno veneciano con la esperanza de que la ley protegiera su nombre por principios éticos, o por lo que hoy conocemos, como los derechos de autor y propiedad intelectual. Dos conceptos que por aquel entonces todavía no existían. Durero, sin embargo, no ganaría del todo esta trifurca, puesto que las autoridades sólo prohibieron el uso indiscriminado de su nombre y monograma en territorio veneciano.

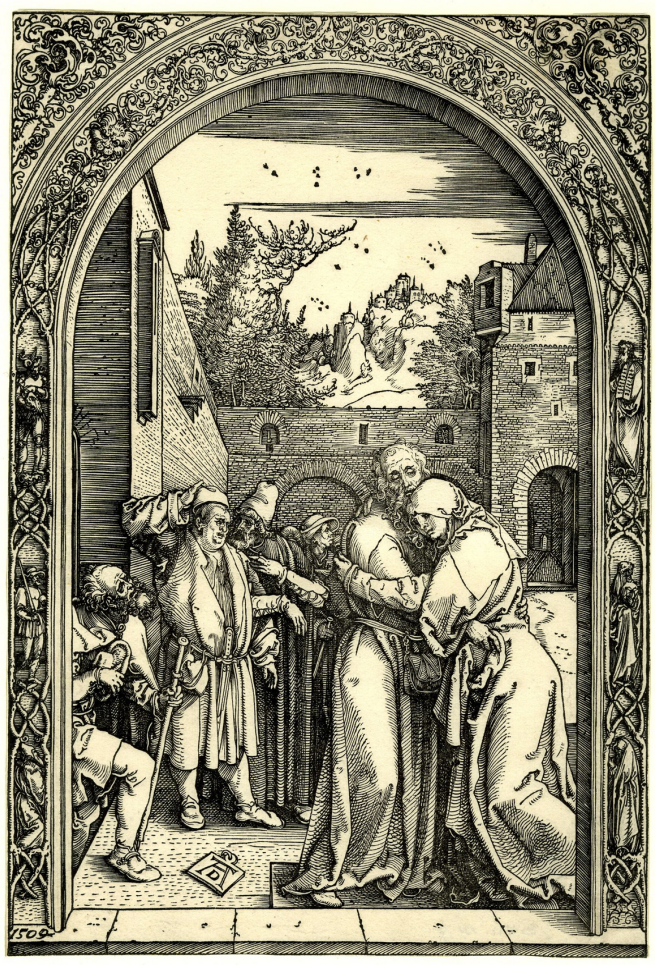

Figura 1. Albrecht Dürer (1471-1528), Serie Life of the Virgin, "Meeting of St. Anne and St. Joachim at the Golden Gate", (1504). Xilografía. Dimensiones: Alto $294 \mathrm{~mm}$, ancho, $207 \mathrm{~mm}$. Firma y fecha grabado en la matriz. (C) The Trustees of the British Museum. 


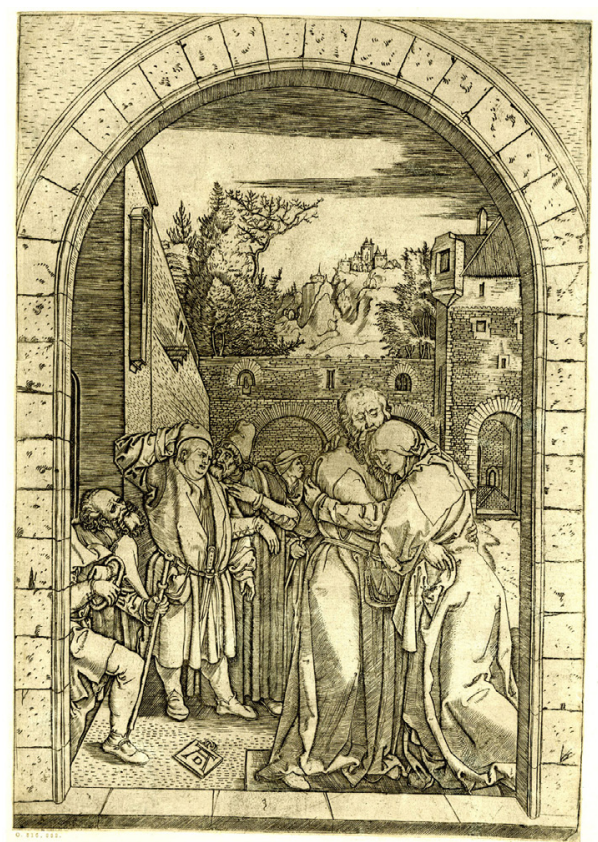

Figura 2. Marcantonio Raimondi (c.1480-c.1534), "Meeting of St. Anne and St. Joachim at the Golden Gate”, (1510-1515). Xilografía. Dimensiones: alto $292 \mathrm{~mm}$, ancho $206 \mathrm{~mm}$.

(C) The Trustees of the British Museum.

Tendríamos que esperar hasta el s. XVIII, para que el derecho de propiedad intelectual de los grabadores cobrara forma. El 7 de febrero 1735, un grupo de artistas formado por George Vertue, George Lambert, Isaac Ware, John Pine, Gerrard Vandergucht, John Goupy y William Hogarth, este último responsable del equipo, decidió presentar ante la inglesa Cámara de los Comunes (House of Commons) The Case of Designers, engravers etchers, \&c. 8 (1735); un escrito en el que exponían la necesidad de que la ley amparase sus derechos de autor, así como de las múltiples estafas y pérdidas que les ocasionaban las ediciones piratas de sus grabados (fig. 3) y así, esta ilícita práctica fuera por fin, punible ante la ley y la sociedad. (Bartual, R., 2010).

Tras constantes revisiones por parte del Parlamento británico, una nueva ley a la cual llamaron Engravers' Copyright Act London (1735), 8 Geo. II, c.13 entró en vigor el 25 de junio de ese mismo año. En dicha ley se reconocía, por primera vez, que como el valor de una obra gráfica radicaba en la particular manera que tenía un artista de representar y hacer un tema, lo más loable era ceder a su mismo creador los derechos exclusivos de imagen, impresión y reimpresión de su grabado o diseño durante un período de catorce años a partir del mismo día en la que éste los publicara por primera vez. Eso sí, con la condición de que en la matriz se grabara el nombre del titular y además se hiciera constar, en cada una de las publicaciones de la obra, su autoría en los créditos. 


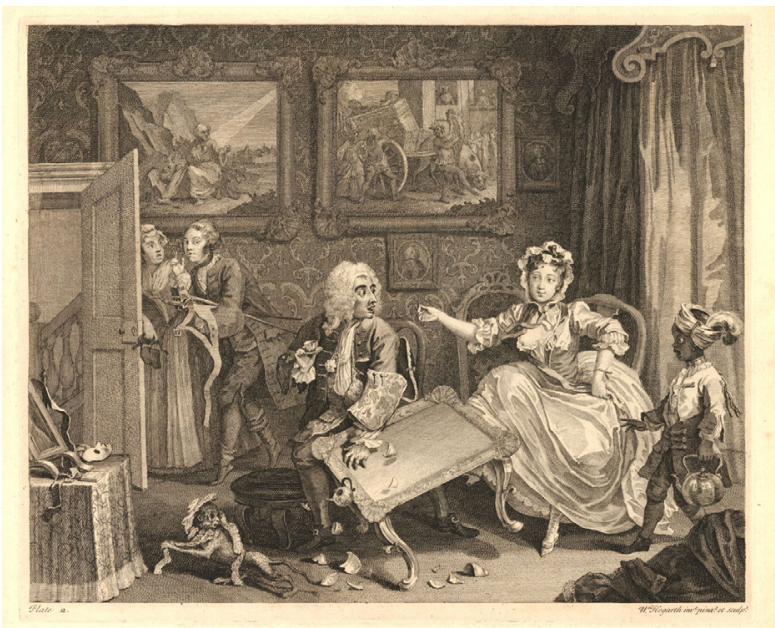

Figura 3. William Hogarth. Serie "A Harlot's Progress", Plancha 2: "Moll as mistress of a Jewish merchant hides her lover. Cosmetics, a theatre mask, and salacious paintings adorn her apartment", (1732), grabado. Dimensiones: altura, $312 \mathrm{~mm}$, por $378 \mathrm{~mm}$. Anchura. (C) The Trustees of the British Museum.

Por su parte, la invención de la fotografía y el rápido perfeccionismo de las técnicas fotomecánicas en el s. XIX, promulgaron varios hechos directamente correlacionados. Por una parte, como el grabado dejó de tener el dominio como reproductor de la imagen, se inició la necesidad de reorientar la naturaleza de su oficio y ahondar mejor en otras virtudes del medio como las estéticas, formales, temáticas, técnicas, etc. Cuestiones que, en otras épocas, parecían más bien secundarias.

Por otra parte, mientras que los grabadores salían de esta pequeña depresión y se encontraban a sí mismos, el vertiginoso perfeccionismo de las técnicas mecánicas hizo posible la venta fraudulenta de falsificaciones que reproducían fielmente la obra gráfica de algún artista; reproducciones firmadas a mano aunque no intervenidas por el autor directamente, pero sí cotizadas como originales. Además de la aparición de reimpresiones de placas y segundas ediciones sacadas al mercado sin permiso del autor o la comercialización de simples imágenes de gran atractivo visual adquiridas ignorantemente a precio de oro. En definitiva, un sinfín de negocios fraudulentos que afectaron tanto a los coleccionistas como a los compradores más inexpertos.

La urgencia del tema hizo que prácticas de antaño que no tenían importancia de repente la cobrasen. Por ejemplo, a finales del XIX, artistas como Whistler o Seymour Haden tomaron la costumbre de manuscribir en sus estampas la abreviatura imp. (como evidencia de que ellos mismos habían sido los artistas impresores), así como su firma, poniéndola a lápiz justo debajo de la huella de la placa estampada y al lado derecho, tal y como lo hemos ido transmitiendo de generación en generación hasta la actualidad.

La gran parte de la revolución ideológica gestada en el siglo XIX respecto al concepto de reproductividad en la obra gráfica en contraposición con la fotografía 
como una manera de "popularizar la información" tal y como la entendía el crítico de arte Philippe Burty, fue liderada por la Société des Aquafortistes Français (18621867) y otra serie de Amateurs etching societies, quienes introdujeron sustanciales cambios en la visión que se tenía acerca del arte de la estampación y, en consecuencia, del estatus artístico del impresor.

Bajo una postura clásica, los impresores debían centrar sus esfuerzos en obtener reproducciones fidedignas al acabado que la matriz presentase como si se tratase de verdaderos productos clonados en serie. El triunfo de la filosofía del l'art pour l'art y el reciente valor que cobró la representación del Tiempo Fugitivo fueron algunos de los factores más importantes que motivaron dicho cambio. Curiosamente, la fotografía despertó en el artista y la sociedad en general, el deseo de ver reflejado en el arte gráfico un proceso que la fotografía no podía proporcionar al hombre: el registro del proceso de la creación.

En dicho sentido, aparece primero la revaloración nostálgica de las pruebas de estado $(\mathrm{P} / \mathrm{E})$ por tratarse del mayor de los registros del proceso de creación y la representación del tiempo y, segundo, la admiración materialista de las Pruebas Únicas de Artistas (P.U.A.). Tras quedar atrás uno de los mayores condicionantes del grabado: la reproducción perfectamente seriada, técnicas como el entrapado, la poupée o el monotipo, así como la experimentación con diferentes tintas y papeles en cada prueba o la iluminación a mano de las estampas con tinta china o acuarela, desataron una nueva forma de entender el proceso de estampación. A partir de dichas prácticas, como anotábamos principalmente lideradas por estas agrupaciones de artistas, el oficio de estampar pasó a ser un arte en el que ahora el impresor o artista sentía la necesidad de imprimir sus matrices desde un concepto mucho más experimental. Una actitud que muy pocos habían liderado hasta el momento, salvo artistas de la talla de William Blake, por ejemplo-, y que propició, tanto que estéticamente las estampas fueran más expresivas, gestuales, creativas e intuitivas, como un evidente distanciamiento conceptual entre la idea de copia de siglos pasados y la idea de original múltiple. Así nos lo demuestran las obras de Dêlatre o Lepic durante los sesenta; éste último autor, inventor de "Versátile eau-forte mobile" o "Mobile Etching". Y, dos décadas más tarde, artistas como Degas y Pizarro. Todos ellos, personalidades que Máxime Lalanne denominaría en su Traité de la gravure à l'eau-forte (1866) (trad. al inglés en 1890) como artistas pintores de "grabados de intención o capricho", en oposición al artista grabador o grabador profesional, a quien Lalanne creía totalmente esclavizado y cegado por la perfección técnica.

Paralelamente, en concordancia con los valores capitalistas y fines mercantiles de valoración, tasación, promoción y venta de la obra, los grabadores comenzaron a creer en la idea de restringir el tiraje de una obra y la cancelación de la matriz una vez concluida la edición. Y aunque, los miembros de la decimonónica Société des Aquafortistes sí realizaban tiradas muy largas hasta 1865, la cancelación de las placas y la firma de las estampas fueron desde entonces un hábito muy común para las generaciones venideras, sobre todo, gracias a las aportaciones de Whistler (fig.4), Seymour Haden, Meryon y Toulouse-Lautrec quienes, como sus contemporáneos, confiaban fielmente en que este nuevo hacer legitimaría la autenticidad de la estampa y les protegerían, en cierto modo, de futuras ilegalidades. 


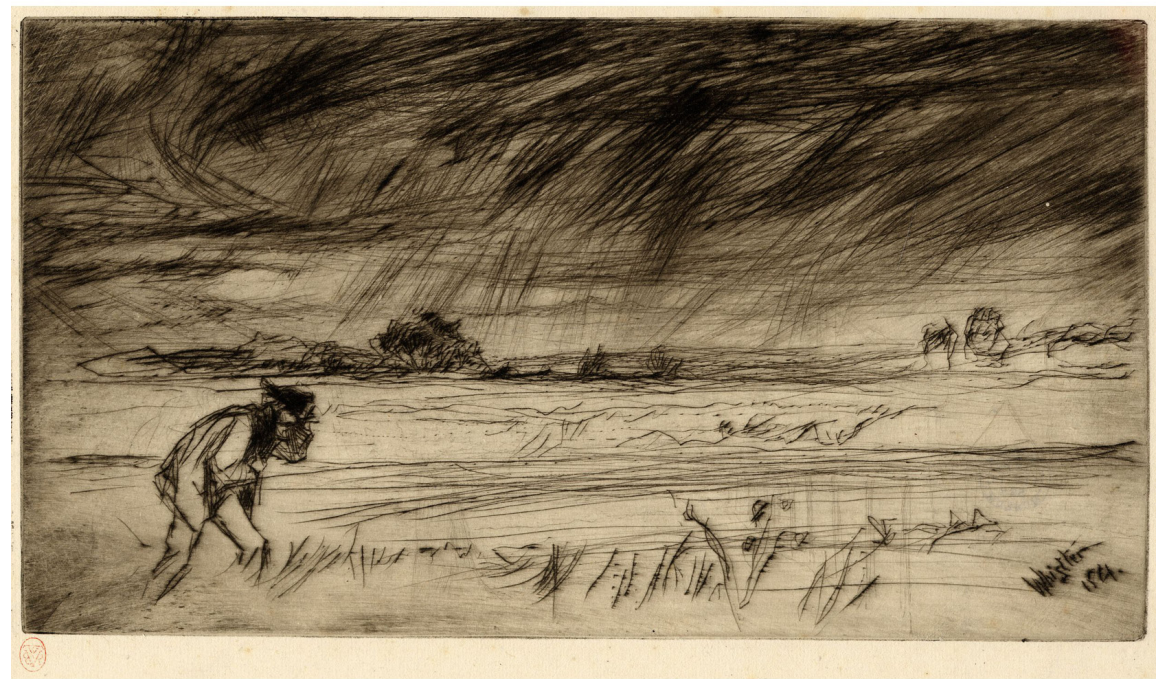

Figura 4. James McNeill Whistler, “The storm”, (1849-1876) Aguafuerte.

Impresor: Auguste Delâtre. Dimensiones: 244 x $321 \mathrm{~mm}$.

(C) The Trustees of the British Museum

Asentado el afán por la experimentación desde finales del S. XIX, la idea de proceder desde una visión más experimental y dialógica con otro tipo de disciplinas, dio paso al origen de talleres tan importantes como El Atelier 17 inaugurado en París (1927-1955) de la mano de William Hayter. Workshop abierto a todo aquél que deseara explorar libremente las diferentes posibilidades creativas de cada uno de sistemas de estampación, es decir, "a communal workshop in which there were no trade secrets and any technical discovery was common knowledge for the benefit of the entire group". (Moser, J., 1978, p. 2).

Bajo este contexto, no será hasta 1937, cuando a nivel mundial surja un interés formal por definir qué características o condiciones debía tener una estampa para poder ser considerada "original". A partir de este momento, el medio por excelencia a través del cual se oficializarían las premisas básicas debatidas entre artistas, amateurs modernos, coleccionistas, impresores, tratadistas, museógrafos dedicados a la adquisión, conservación y exposición de estampas, y representantes de gabinetes e instituciones públicas o privadas, fueron las actas de congresos de alcance internacional realizados con cierta asiduidad.

Como anotamos, los primeros acuerdos se establecieron en 1937. Año, en el que motivados por mostrar y debatir en torno al estado y últimos avances en el campo de la ciencia, la tecnología y el arte, la ciudad de París decidió albergar una de las más conmemorables exposiciones reguladas por la oficina internacional de exposiciones Bureau International des Expositions (BIE): la "Exposition Internationale des Arts et Tecniques Dans la vie moderne" conocida más bien, en términos sencillos, como la "Exposición Internacional del 37". 
Dentro de este magnánimo evento celebrado entre el 25 de mayo y el 25 de noviembre de 1937, se congregaron a lo largo de 185 días, 44 países para la celebración de más de 600 congresos. Obviamente, la introducción de procedimientos mecánicos y fotomecánicos en los últimos años para la reproducción de la imagen, había generado una cierta incertidumbre en varios estratos de la vida artística, afectando tanto a artistas como a comerciantes, coleccionistas y productores, dada la falta de legislación y reflexión conceptual. ¿Qué era una obra original en las artes gráficas? ¿Una reproducción realizada mediante procesos fotomecánicos, pero firmada a mano por un artista, debía considerarse también como obra original?

Para hallar respuesta a éstas y otras preguntas, se dio apertura al Congreso Internacional de Grabado el 6 de julio de 1937 bajo la presidencia del destacado editor y galerista parisino Sr. Marcel Guiot. En él, participaron como centro neurálgico la Chambre Syndicale de l'Estampe, du Dessin et du Tableau y el Comité National de la Gravure Française presidido por Julien Cain, por aquel entonces, el administrador de la Biblioteca Nacional de París. Empresa a la que se sumaron otra serie de personalidades de la época que actuaban como delegados extranjeros: el historiador del arte Campbell-Dogdson (Gran Bretaña), los grabadores Kiyoshi Hasegawa y Yoshijiro Urushibara (Japón), el historiador y crítico de arte Ragnar Hopp y el artista Eric Detthow (Suecia), Ekman (Países Bajos), Grosfils y Lebber (Bélgica), Petrucci (Italia), Bernouilli y Daniel Baud-Bovy (Suiza) y Webster (USA), entre otros.

Esta especie de concilio, comprensiblemente no sólo tenía la finalidad de generar debate y reflexionar en torno a la problemática del grabado en sintonía con el contexto dado en el que se encontraban. Establecer un acuerdo sólido y delimitar con la mayor precisión posible una definición de grabado original a través de una redacción explicativa de los porqués de sus discernimientos y conclusiones derivadas ad hoc votadas y consensuadas, era en definitiva su esencia.

Una de las ideas principales fue mantener un firme apoyo a la figura del artista en cuanto hacedor-creador de lo auténtico y, por ende, de lo original en oposición a lo mecánico, tal y como venía postulándose desde 1857 por John Ruskin. El acta final del congreso apuntaba claramente este principio básico que, de manera definitiva, quedaría asentado tal y como alude, la definición del término de estampa, que en 1990 publicaría la misma parisina Chambre Syndicale de l'Estampe et du Dessin en su guía técnica:

"Sont considérées comme gravures, estampes et lithographies originales, les épreuves tirées en noir ou en couleurs, d'une ou plusieurs planches, entièrement conçues et exécutées à la main par le même artiste, quelle que soit la technique employée, à l'exclusion de tous procédés mécaniques ou photomécaniques. Seules les estampes répondant à cette définition ont droit à l'appellation la belle estampe". (Chambre Syndicale de l'Estampe et du Dessin, 1990, s/p.).

No obstante, como en todos los campos de conocimiento, las posibles disyuntivas, grietas o inconformidades dadas a posteriori por artistas o críticos de arte, las encontramos relatadas en libros colectivos, artículos y ensayos de opinión. Medios perfectos con los que se fueron perfilando cada vez mejor dichas delimitaciones a un contexto cíclicamente cambiante. 
En el área de la gráfica, las opiniones que mayor peso tuvieron, vinieron de la mano de muchos de los miembros del Print Council of America. Uno de los compendios en formato de libro más relevantes en torno al tema fue What is an Original Print?, coordinado y editado por Joshua Binion Cahn, en New York en 1961.

Este pequeño documento de no más de treinta páginas, fue el resultado de un proyecto de investigación emprendido por la misma asociación en 1960 justificado como "(...) an increased necessity for standards of originality and for Knowledge of artistic and trade practices". (Lessing, 1961, p. 6)

$\mathrm{Su}$ objetivo principal fue el de proveer una especie de almanaque de los debates del consejo y conclusiones resultantes en torno al cuestionamiento qué era una obra gráfica original como guía básica para artistas, editores, comerciantes, coleccionistas y público en general. En la publicación hallamos aportaciones como las del vicepresidente del consejo Mr. Carl Zigrosser, quien elaboró una fantástico artículo titulado "The historical background" sobre la evolución conceptual que el concepto de original había tenido a lo largo de la historia del hombre (en Binion Cahn, L., 1961); y otra serie de colaboraciones de la mano de la crítica de arte Dore Ashton, o los galeristas Mr. Peter Deitsch y Mr. Herman B. Wechsler. Siendo su mayor aportación, la extendidísima definición de estampa original a través de la redacción de tres puntos básicos:

"What is an original print? An original print is a work graphic art, the general requirements of which are:

1. The artist alone has made the image in or upon the place, stone, wood block or other material, for the purpose of creating a work of graphic art.

2. The impression is made directly from that original material, by artist or pursuant to his directions.

3. The finished print is approved by the artist". (Binion Cahn, 1961, p. 9).

Comprensiblemente, muchos de los contenidos tratados por The Print Council of America, fueron debatidos o reafirmados antes de su publicación en 1961, en el Congreso Internacional de Artistas de Viena celebrado en septiembre de 1960, de nombre original: Third International Congress of Plastic Arts. Uno de los congresos más elogiados hasta el presente por sus aportaciones hacia el tema en el cual, Gabor Peterdi actuó como el representante de los artistas gráficos del consejo.

Sin lugar a dudas, este congreso nos brindó muchos de los principios más significativos que barajamos como artistas gráficos hoy en día. Por una parte, se estableció fehacientemente que para que una obra gráfica fuese original, la plancha debía haber sido ejecutada por el mismo artista, pudiéndose en el caso de la estampación de la misma, delegarse a un profesional bajo su dirección. La firma de la estampa quedó, asimismo, como una práctica normalizada y como medio de autentificación de la pieza, especificando, eso sí, que jamás podría considerarse original a una reproducción realizada por procedimientos mecánicos, aunque fuese una copia idéntica de una obra de arte, estuviera firmada personalmente por el autor o sujeta a una edición limitada corta o larga. 
Pero lo más interesante fueron los aportes de la edición de las placas como derecho exclusivo de su autor, la numeración de las estampas con la indicación $\mathrm{X} / \mathrm{X}$ que, aluden a la regulación del tiraje de una plancha, siendo el numerador $(1 / \mathrm{x})$ el que especifica la posición que esa estampa ocupa individualmente dentro de una serie mayor, y el denominador $(\mathrm{x} / 30)$, el que expone cuántos ejemplares en total componen la edición; hasta la legitimidad y derecho otorgado al autor para cerrar posibles reediciones de sus placas con la introducción de la praxis de la cancelación o destrucción de la matriz.

El acta final del congreso, cerraba asimismo, aspectos más concretos como la aprobación de las "Pruebas de estado" o las "Pruebas de Artista" delimitando, en este último caso su tiraje a un $10 \%$ del total de la edición, el uso de siglas y tipo de numeración (como 1/30, I/III P/A, lera P/E, etc.), la figura y funciones del estampador - impresor, e incluso, la definición de las técnicas y métodos más comunes en el campo de la gráfica reproducible. (Cabo de la Sierra, G., 1979)

En definitiva, los cinco principios básicos que la Association Internationale des Arts Platiques (Asociación Internacional de Pintores, Grabadores y Escultores) de la UNESCO y el Kingdom National Committee (Comité Nacional del Reino Unido) establecieron por unanimidad para definir "estampa original", como las dos grandes comitivas que lideraban el Congreso, fueron:

1. Il appartient à l'artiste graveur, et seulement à celui-ci. De fixer le nombre définitif de chacune de ses œuvres graphiques dans les différentes techniques : gravure, lithographie, etc.

2. Chaque planche, pour être considérée originale, doit porter non seulement la signature de l'artiste, mais également l'indication du nombre total des tirages et le numéro de série de la planche. L'artiste peut également mentionner qu'il a luimême procédé au tirage.(a)

3. Il est souhaitable qu'une fois les estampes tirées, la planche d'origine soit rayée ou qu'elle porte tout autre signe distinctif indiquant que le tirage est terminé.

4. Les principes sus-indiqués s'appliquent aux œuvres graphiques qui peuvent être considérées comme originales c'est-à-dire à des œuvres imprimées dont les planches ont été exécutées par l'artiste. Les œuvres qui ne répondraient pas à ces conditions devraient être considérées comme des « reproductions ».

5. En ce qui concerne les reproductions, aucune règle n'est possible. Toutefois, il est souhaitable que les reproductions soient déclarées comme telles et, par conséquent, distinguées sans aucune équivoque possible des œuvres graphiques originales. Ce principe s'applique particulièrement aux reproductions d'une qualité telle que l'artiste, désirant reconnaître le travail matériellement exécuté par l'imprimeur, s'estime pleinement justifié à les signer.

Nota (a). Aux Etats-Unis d'Amérique, l'artiste qui a lui-même procédé au tirage de ses planches fait suivre sa signature des lettres «Imp.» (impressit)". (Binion Cahn, 1961, p. 28. 
Por otra parte, Inglaterra, famosa por su interés en ahondar en la tasación y valoración histórica y económica de las obras de arte, sobre todo desde los aportes de Gerald Reitlinger sobre economía del arte en los años sesenta, en 1963 el Kingdom National Committee retoma la definición estipulada por el III Congreso Internacional de Viena haciendo una serie de puntualización adicionales:

"A propósito de esta definición, los grabados originales deberán ser clasificados en Gran Bretaña como siguen:

(a) Todas las estampas tiradas en negro o en color, por medio de una o más planchas, piedras, pantallas, bloques de madera, de linóleum, etc. Predominantemente ejecutadas por la mano del artista, sea de su propio diseño o interpretando el trabajo de otro artista, o como resultado de una colaboración.

(b) (I) las láminas originales pueden ser reproducidas en ediciones limitadas. Ediciones limitadas son aquellas en que los artistas han decidido tirar un determinado número. (II) Láminas tiradas por el artista para demostrar el progreso. Llamado "primer estado" o "segundo estado", etc. y pruebas de artista, las cuales son generalmente limitadas al $10 \%$ del tiraje total y deben llevar una indicación a ese efecto, no debiendo ser incluidas en la numeración total del tiraje. (III) Si no se indica el tiraje total, las láminas se exponen a ser consideradas de tiraje ilimitado y por ello sujetas a impuestos de compra en este país e impuestos de importación en el extranjero.

(c) El impresor, si es otro que el artista, puede añadir el nombre en la lámina.

(d) Tirajes que no pueden ser clasificados como estampas originales son los siguientes: (i) Copias de trabajos originales de arte por procedimientos fotomecánicos, u otra mecánica cualquiera, aunque sean en ediciones limitadas y lleven la firma del artista cuyo trabajo ha sido reproducido. (ii) Estampa que pueden ser descritas como copia pareja o literal de un trabajo original de arte, esté como esté reproducido.

(e) Es deseable que en este país las reproducciones se reconozcan como tales y así distinguirlas de los originales, al imprimir en ellas el nombre del artista, editor e impresor, aun cuando las estampas vayan firmadas, o firmados "facsímile" por el artista cuyo trabajo se ha reproducido". (Berenguer, A. 1996, pp. 225-230).

A partir de ahora, las ampliaciones al tema serían continuas. En diciembre de 1964, forjaron también sus aportes el Comité National de la gravure française con una nueva definición del término original posteriormente aceptada por la Cámara Sindical de L'Estampe et du Dessin y, que más tarde saldría publicada en la revista recién inaugurada, Nouvelles de l'Estampe en febrero de 1965, y la Guilde Internacional de Litografía en Ostende (Bélgica) en 1969.

Sin embargo, las fuentes que en mayor medida propiciaron el debate fueron algunas de las cartas remitidas al boletín neoyorkino $\mathrm{n}^{\circ} 2$ del Print Collector's Newsletters 3, publicado en 1972. Ejemplar que contenía varios ensayos diferentes que correlacionaban la acepción de "original" con el estado del grabado y el término de "original print". El primero de ellos, de la autoría de Richard Field propone una reflexión muy interesante. El autor nos recuerda que el concepto de original no debería izarse de una manera tan restrictiva en este campo ya que la estampa, es ante todo un multi-original. Idea básica que Field hilvana, a posteriori, a la necesidad de 
ahondar en las posibles grietas que las definiciones anteriores hacían brotar. Por una parte, Field comenta que al interrelacionar lo original con la elaboración de la imagen de la mano del artista exclusivamente, no explica del todo la realidad. Para exponer sus ideas, el autor nos propone un ejemplo: la serie de fotoserigrafías Flowers que Andy Warhol realizó entre 1964 y 1970.

La imagen que Flowers representa, la de unas flores, no había sido originada por el mismo Warhol, sino que éste la tomó de una fotografía de Patricia Caulfield publicada en 1964, para poder trabajar a partir de ella. La problemática estaba servida en bandeja. Si el verdadero autor de la imagen no era Warhol, ¿la decisión de apropiársela, rescatarla y/o procesarla eran razones suficientes para considerar ese nuevo resultado como un original del artista? En realidad aunque Warhol fuera demandado por la autora de la fotografía, hoy no podemos negar la naturaleza innata de los procesos creativos del arte en un tiempo como el nuestro en el que la imagen está sujeta a la condición postmedia (Brea, J.L., 2001). Pero, ¿en los años sesenta, tenía cabida pensar que Warhol estaba plagiando a Caulfield? ¿Debíamos seguir pues postulando que la imagen de una placa tenía que ser realizada por el artista para ser considerada como un original?

Estos cuestionamientos nos llevan a un planteamiento muy simple: que una obra gráfica sea original no parte del hecho de que el artista haya sido partícipe como único autor a lo largo de todo el proceso de creación de una obra desde su origen hasta el final, o simplemente porque haya tocado el medio. Su acepción como original, se haya más bien, en la autenticidad que el artista confina a una obra de arte a través del proceso de su creación porque él es el motor y el porqué de su resultado, desde la ideación o apropiación de las imágenes al origen de los medios, métodos o procedimientos que pueda elegir hasta la finalidad a la que destina la obra. Factores que, evidentemente, son los que determinan la pregnancia de una obra de arte y la latente huella del característico lenguaje de su creador.

Otro de los artículos publicados en el $\mathrm{n}^{\circ} 2$ del Print Collector's Newsletters de 1972 a tener en cuenta, es el June Wayne. Wayne, centra su atención en que, aunque la praxis de ahondar en la delimitación de ciertos términos como original, grabado, edición, etc. son justificables por la necesidad de ahuyentar males como el de la falsificación, la devaluación o la desconfianza y por ende, proteger los derechos de los consumidores y creadores, no nos obliga a cerrarnos en banda a definiciones rígidas y estáticas postuladas como patrones irrevocables porque obviamente, éstos irían en contra de lo nuevo.

"As an artist, I follow an aesthetic imperative. When I am in hot pursuit of a new vision, I cannot pull up short to obey a verbalization of how to solve an aesthetic problem that neither I nor anyone else has solved before. And it is exactly when in conflict with a process, serving a new aesthetic, that I am most apt to make a creative advance. (...) Yet once I have completed a work of art, I am more than willing to guarantee what it is - a disclosure that only I, as the artist, can truly make.(...). At that point, if what I created fits the definition, well and good, If not, it is the definition that lacks scope and must give way, for definitions by their usage, just as language changes its meaning to suit the needs of populations. (...) 
"No one demands a definition of an original painting. On the face of it, it seems a silly idea. But painting share the same semantic, issues and questions of procedure as do the printmaking arts - that is, the same issues except one: that the print can exist in editions there's the rub. But is it so difficult to understand that in a set of look - alike triplets, all three are original?" (Wayne, J. en Austin G. et al., 1972, p. 29).

Llegados a tal punto en el que irónicamente Wayne nos plantea cómo podemos seguir dudando de la originalidad de unos trillizos o, parafraseando a Kako Castro (2007), ¿quién duda de la originalidad de un billete de 100 euros y exige la placa?, pocos serían los momentos en los que la sociedad volvería a retomar este debate.

Las próximas aportaciones al tema, más bien vendrían enfocadas a resolver ciertas actualizaciones en lo referente a la inclusión o el debate de tomar en cuenta las aportaciones de otras técnicas no contempladas anteriormente o, simplemente a publicaciones en los que se pormenorizarán algunas propuestas en concreto como las relacionadas con el campo de la edición de una obra por poner un ejemplo.

Concretamente, en 1990 aparece $A$ Code of Ethics for the Original Print, la primera publicación editada por el Conseil Québécois de l'Estampe (CQE) de Quebec en formato bilingüe de francés a inglés. Obra, en la que además de tratarse las normas de edición, Richard Ste-Marie y Nicole Malenfant abordan todo tipo de paradigmas en torno a la estampa original y el grabado contemporáneo en general. En la segunda edición de $A$ Code of Ethics for the Original Print publicada en junio de 2000 (1era ed. 1990), las ampliaciones de la introducción realizadas por Richard Ste-Marie apuntan a muchos de los debates actuales.

Por una parte, parece aceptarse la posibilidad de que reducir los límites que pudieran definir dónde termina lo manual y dónde lo mecánico en correlación con lo original, es indescifrable e inane sin previamente reflexionar sobre términos de autenticidad y los posibles aportes de innovación hacia el campo. Por otra parte, Ste-Marie entiende que la introducción de las nuevas tecnologías de la imagen e impresión, siempre son recibidas con gran entusiasmo por los grabadores como nuevas prácticas porque, en términos de supervivencia, les inspira a retroalimentar su poética y saciar su afán experimental. Refiriéndose a los artistas, Ste-Marie comenta lo siguiente:

“Conscients d'appartenir à la tradition de l'estampe, ils accueillent l'arrivée de ces nouvelles technologies en continuité avec les anciens modes de production dont ils cherchent ainsi à garantir la survivance. Ils explorent de nouveaux médias du point de vue esthétique, convaincus que dire une chose d'une nouvelle manière amène souvent à dire autre chose, les nouveaux outils permettant de poser un regard neuf sur les particularités de la réalité contemporaine. Tout comme leurs prédécesseurs, ces artistes tentent de développer leurs nouveaux instruments en les adaptant à une pratique poétique personnelle, les détournant pour ainsi dire de leur vocation commerciale et industrielle. De cette façon, et à leur manière, les artistes qui utilisent ces nouvelles technologies contribuent au renouvellement des deux piliers de la tradition de l'estampe: l'élargissement du champ de la pratique et le développement du métier". (Ste-Marie. et al., 2000, s/p).

Tomando en cuenta, la intrínseca forma de ser del artista gráfico, no reconocer las praxis y los aportes que las tecnologías y medios más recientes podían ofrecer al 
campo del grabado y a la misma poética y renovación idioléctica de los artistas, sólo porque en las actas y los diccionarios no se contemplaban, era un sinsentido.

Así, en base a lo aprobado el 25 de octubre de 1991 por una comisión internacional a colación de la celebración del III Congreso de Venecia, se incorporaron al campo del grabado la fotocopia, el reporte fotográfico, grabado fotoquímico, la película lith y la manipulación de las imágenes realizadas a partir del ordenador, es decir la estampa digital.

El principio básico de esta aceptación era que dichos medios de expresión, compartían con el grabado tradicional la paradigmática paradoja de lo único y lo múltiple. Una obra digital, por ejemplo, compartía la misma idea de multiplicación a partir de una única matriz, pues aunque ésta no fuera una placa sino un archivo grabado dentro de una computadora u otro dispositivo de almacenaje, podíamos reproducir la imagen con una edición limitada a diferentes soportes y, consecuencia, compartir el mismo sistema de numeración.

Finalmente, en 1996 el Conseil québécois de l'estampe reafirma la propuesta y acepta tres nuevas prácticas: el copygraphy, el arte impresión offset y lo digital, basándose en las justificaciones promulgadas en la bienal de 1991, y los II y III Symposiums internationaux d'offset d'art, celebrados respectivamente en Vila Praïa de Ancora, en Portugal en 1991, y en Trois-Rivières, en 1993.

\section{Hacia la construcción de un nuevo concepto de original en la gráfica}

Como bien argumentaba June Wayne (1972) hace ya más de treinta años, el debate que envuelve al arte gráfico seriable y lo original seguirá subsistiendo mientras el arte siga anclado al sistema capitalista interesado en el valor mercantil del beneficio de la plusvalía, y por ende, de la necesidad de tasar y regular la circulación y comercialización de la obra de arte como un producto financiero.

Este debate, se torna caduco pues aunque actualmente vivamos en una época en la que los medios de comunicación masiva hayan generado un alto porcentaje de inflación de la imagen generada por los creativos de las artes aplicadas (diseñadores, dibujantes de cómics, dibujos animados, etc.), no tiene nada que ver con las imágenes y obras realizadas por los artistas, pues ellos no enriquecen la realidad con fines mercantiles.

La praxis del arte gráfico actual es muy diferente. Hoy en día, los artistas reconocen que el arte gráfico seriable además de poseer rasgos idiomáticos y estéticos propios como medio de expresión independiente (Martínez Moro, J., 1998), tiene una particularidad muy especial que facilita la transversalidad con otras técnicas e incluso disciplinas; lo cual le dota de una extraordinaria adaptabilidad y polivalencia a los contemporáneos y venideros procesos de hibridez.

Como bien sabemos, si hay algo que verdaderamente queda manifiesto en este arte, es la apertura y versatilidad procesual que en elaboración creativa reside. Para la consecución de una obra gráfica, el artista labora transitando por varios pasos. En primera instancia, genera la idea comúnmente formulada como imagen; después elabora la matriz o placa; posteriormente, transfiere la imagen de la matriz a un soporte de características bi o tridimensionales mediante diferentes métodos de estampación, 
impresión o proyección; para finalmente, concurrir en un determinado acabado, ya sea como un ejemplar impreso único, un tiraje de edición limitada, e incluso, si así lo desea el artista, como una obra postproducida en otro formato menos convencional (Bourriaud, N., 2007) Las perspectivas que estas diferentes etapas ofrecen a un artista gráfico son realmente infinitas $\mathrm{y}$, en dicho sentido, algunas de las complejas resoluciones procesuales no necesariamente tienen que estar sujetas al concepto de original (como matriz) y multioriginal (como las "copias" resultantes de dicho original). Y muchos menos, al pretérito precepto que relacionaba restrictivamente el original con la matriz y la copia, con la reproducción impresa.

Algunos artistas simplemente deciden no trabajar sus estampas como "workingproof" (W/P), es decir, un multi-original intervenido a mano a posteriori. Otros, toman la determinación de exponer las matrices y, otros, por el contrario, juegan a postproducir sus grabados como animaciones, ensambles objetuales, etc.

Actualmente, las perspectivas que el arte gráfico seriable tiene de interactuar y manifestarse como prueba única, estampa editada, objeto artístico, múltiple o en el espacio gráfico físico o virtual son propiamente virtudes que demuestran que no estamos ante un almanaque de técnicas con las que podemos reproducir una imagen, sino ante un medio de expresión de gran fecundidad innovadora que entiende que la reproductibilidad, la seriación, e incluso el acto de imprimir o transferir la imagen sobre un soporte físico, han pasado a ser posibilidades y no requerimientos escolásticos

En dicho sentido, una obra gráfica es aquella en la que se vislumbra la armonía correlacionada entre la incuestionable particularidad idioléctica de los medios y las técnicas gráficas del grabado y los sistemas de estampación e impresión (tradicionales y nuevos), y la elección de tomar dicha poética como el medio de representación con el que expresar su visión del mundo. Siendo ésta original, si evidencia en cada uno de los pasos y elecciones dados por el autor, la voluntad creativa y su particular manera de concebir y llevar a cabo el proceso de creación aún y cuando se imbrique con otros medios o técnicas propiamente no afines al arte gráfico.

En dicho sentido, cabría hablar en términos de obra gráfica seriable, impresa o no impresa en lugar de obra gráfica original seriada e impresa, pues muchas de las aplicaciones actuales toman el concepto de seriar o imprimir como una opción a desbancar durante el proceso de creación de la obra, a la par que conciben a lo original, al proceso en sí mismo, a veces ni al resultado, y mucho menos a la matriz.

Actualmente, nuestra manera de generar conocimiento en las áreas del arte, la tecnología y la ciencia, hace patente una latente inclinación por parte de los creadores e investigadores a jugar bajo el rol de la praxis y teoría multi, inter, y transdisciplinar. La ruptura de las viejas fronteras, debe alentarnos a huir de posiciones deterministas en las que toda configuración de un medio de expresión tenga que ser normativizado, si dicha normatividad apuntara a la exclusión de nuevas formas de actuación.

El continuum cambio no debe entenderse como un fenómeno negativo, como en lo particular, que surja una nueva técnica o que algún artista realice obra gráfica difícilmente categorizable no tendría que ser un obstáculo. Si las definiciones actuales no cubren la praxis de nuestro presente es porque, dichas postulaciones poseen una deficiencia conceptual interna y por ello, fracasan. En dicho sentido, si 
hoy proponemos que la denominación más acertada es la de obra gráfica seriable, (impresa o no impresa), ni siquiera significa que ésta sea la concluyente, sino un intento tentativo de entender el proceder y el entendimiento de los artistas en su constante diálogo con la sociedad y el mercado del arte.

\section{Referencias}

Austin, G., Field, R., Prouté, H., Wayne, J.(1972), Alice in Dali-land, Print Collector 's Newsletters 3, $\mathrm{n}^{\circ}$ 2, Ed. Print Collector's Newsletter, inc., New York, pp. 25-29.

Bartual, R.(2010) William Hogarth's A Harlot's Progress: the beginnings of a purely pictographic sequential language, Studies in Comics, Vol. 1, num. 1. Intellect Ltd Editorial, Bristol, abril.

Bently L. \& Kretschmer M., (eds.) (1504) A woodcut by Albrecht Dürer plagiarized by Marcantonio Raimondi, Primary Sources on Copyright (1450-1900), s/f. (www.copyrighthistory.org)

Berenguer Wieden, A. (1996)Aplicación de los materiales sintéticos al collagraph, relieve y color. Tesis doctoral inédita. Valencia:Universidad Politécnica de Valencia, Facultad de Bellas Artes.

Binion Cahn, J. (coord.) (1961) What is an Original Print? Principles recommended by The Print Council of America, New York: Editado por Joshua Binion Cahn,

Bourriaud, N (2007) Postproducción. Los Sentidos/Artes Visuales. Buenos Aires: AH. Adriana Hidalgo Editora, , pp. 7-8.

Brea, J.L.(2001) La era postmedia. Acción comunicativa, prácticas (post) artísticas y dispositivos neomediales. Salamanca: Consorcio de Salamanca,

Cabo de la Sierra, G.(1979) ¿Qué es la obra gráfica original? en Grabados, litografías y serigrafias: Técnicas y procedimientos. Madrid: Esti-Arte.

Castro, K. (2007) Mapas invisibles para una gráfica electrónica (de la huella incisa al grabado con luz) España:Universidad de Vigo.

Chambre Syndicale de l'Estampe et du Dessin, Guide de la Chambre Syndicale de l'Estampe et du Dessin. Ed. Promodis. París, 1990.

Ivins, W.M. Jr (1975) Imagen impresa y conocimiento. Análisis de la imagen prefotográfica. Barcelona:Gustavo Gili, (Edición Original: Prints and visual communication, 1953)

Martínez Moro, J. (1998) Un ensayo de grabado (A finales del siglo XX) Santander: Creática,

Moser, J.71978) The Impact of Stanley William Hayter on Post-War American Art, Archives of American Art Journal, Vol. 18, $\mathrm{n}^{\circ}$ 1, Washington: The Smithsonian Institution, (pp. 2-11)

Ramos Guadix, J.C.(1992) Técnicas aditivas en el grabado contemporáneo. Granada: Servicio de Publicaciones Universidad de Granada.

Ste-Marie R. et al.,(1990) Code of ethics for the original printmaking. Conseil québécois de l'estampe, Montréal, 2000, $2^{\mathrm{a}}$ Ed. Previamente publicado como: A code of ethics for the original print, Conseil québécois de l'estampe, Montréal.

Vives Piqué, R.(2003) Guia para la identificación de Grabados, Madrid: Arco Libros. 